\title{
A EXTERNALIZAÇÃO DA ATIVIDADE PRODUTIVA: O IMPACTO DO TELETRABALHO NA NOVA ORDEM SOCIOECONÔMICA
}

\author{
Christian Marcello Mañas \\ Especialista em Economia do Trabalho, Mestrando em Direito das \\ Relações Sociais pela UFPR, Advogado.
}

\begin{abstract}
SUMÁRIO: Introdução; 1 Trabalho a distância; 2 Trabalho em domicílio; 3 Teletrabalho; 3.1 Definição; 3.2 Subjetividade do tempo de trabalho e a subordinação jurídica como critério definidor da relação de emprego; 3.3 Enquadramento jurídico; 3.4 Variáveis do teletrabalho: vantagens e inconvenientes; 4 Considerações finais; Referências bibliográficas.
\end{abstract}

\section{INTRODUÇÃO}

A crise econômica que assola o mundo, juntamente com os desequilíbrios sociais e políticos, são questões indissociáveis da problemática que se instaura nas relações sociais e no mercado de trabalho. Aliado a isso, as mudanças tecnológicas que se desenvolveram com a informática e telecomunicações implementaram grandes alterações na forma de execução do trabalho, introduzindo novas modalidades de trabalho a distância, o que traz um novo repensar acerca do contrato de trabalho clássico vivenciado no modelo de produção fabril.

Modernamente grande parte da atividade de trabalho está mais relacionada ao tratamento da informação do que propriamente à transformação da matéria, eis que se vive em uma transição da sociedade industrial para a chamada sociedade da informação, a qual se insere na nova ordem econômica.

A forma pela qual o Direito do Trabalho se constituiu passa a ser redimensionada frente à implementação de novas tecnologias da informática e de telecomunicações, que tendem ao exercício da atividade econômica distante cada vez mais do modelo tradicional de produção, que concentrava máquinas e pessoas no interior de grandes fábricas, trabalhando em tempo integral, sob o olhar atento do empregador. ${ }^{1}$

Pode-se dizer que a descentralização do processo produtivo, com a realização do trabalho a distância, deixa de ser visto apenas como trabalho em domicílio clássico, passando a ser concebido sob outra roupagem, com a preponderância do trabalho intelectual sobre o manual, sem a presença física do empregador.

1 As grandes fábricas eram caracterizadas pelos enormes espaços para guarda de estoque de mercadorias, matérias-primas, ferramentas, bem como refeitórios, vestuários e escritórios. Cf. MAGANO, Octavio Bueno. Trabalho a distância. Trabalho \& doutrina, n. 24, 2000, p. 3 e 4. 
O teletrabalho é tema palpitante no Direito do Trabalho atual, dado o destacado papel que referida forma produtiva assume hodiernamente, sendo amplamente debatido nos países desenvolvidos e pouco discutido nos países em desenvolvimento, inclusive no Brasil e demais países do Mercosul.

JAVIER ARANDA afirma que o teletrabalho surgiu nos EUA, nos anos setenta, com a crise do petróleo. Com o fim da crise, tal forma de trabalho apenas emergiu no início dos anos noventa com a utilização da informática e das telecomunicações, pois se objetivava reduzir gastos com o deslocamento dos trabalhadores e, conseqüentemente, reduzir o consumo dos combustíveis e a poluição nos centros urbanos. ${ }^{2}$

A tentativa em demonstrar a natureza jurídica e os caracteres do teletrabalho, em muitos artigos escritos a respeito nos últimos anos, evidenciam a deficiência de um substrato teórico que se faz necessário, pois o teletrabalho, ao contrário do que muitos afirmam, não inova o Direito do Trabalho. ${ }^{3}$ Em que pese ser um modelo que rompe com os padrões clássicos relativos ao lugar e tempo de trabalho, o mesmo deve ser visto na perspectiva de que as relações sociais existentes são complexas e, dessa forma, exigem adaptação à normatividade que rege a sociedade.

\section{TRABALHO A DISTÂNCIA}

O trabalho executado longe dos domínios da organização empresarial, teoricamente sem controle de horário e sem o poder exercido sobre a forma pela qual ele se desenvolve, é traço característico do trabalho a distância, gênero que compreende o trabalho em domicílio, teletrabalho, vendedores pracistas e viajantes, além de representantes comerciais.

No entanto, as novas configurações do trabalho a distância, e as formas pelas quais ele se manifesta hoje, principalmente devido à utilização de tecnologia de ponta nas grandes empresas, acarretam uma nova organização industrial, com o surgimento de relações de trabalho que apontam para o esgotamento do padrão de crescimento fordista, justificando, portanto, que ele se torne objeto de reflexão.

Segundo DAVID HARVEY, essa mudança de paradigma gera "uma série de novas experiências nos domínios da organização industrial e da vida social e política", [...] sendo que tal estrutura adota práticas que não apenas "facilitam muito a exploração da força de trabalho das mulheres em ocupações de tempo parcial, substituindo, assim,

2 Cf. ARANDA, Javier Thibault. El teletrabajo: análisis juridico-laboral. Madrid: Consejo Económico y Social, 2001, p. 19.

3 WASHINGTON LUIZ DA TRINDADE entende que as figuras da terceirização e do teletrabalho, por exemplo, participam do esforço de reinvenção do trabalho, para ajustá-lo às mudanças ditadas pelas revoluções científica e tecnológica e para salvar a estrutura danificada do contrato de trabalho. Ver TRINDADE, W. L. da. Teletrabalho: trabalho a distância. RDT-Revista do Direito Trabalhista, n. 6, 2000, p. 19-20. Por sua vez, PINHO PEDREIRA entende que o modelo de relação de trabalho, sobre o qual se construiu, está em erosão. Ver PEDREIRA, P. O Teletrabalho. Revista LTr, v. 64, n. 5, 2000, p. 583. 
trabalhadores homens centrais melhor remunerados e menos facilmente demitíveis pelo trabalho feminino mal pago, com o retorno dos sistemas de trabalho doméstico e familiar e da subcontratação". ${ }^{4}$

Um aspecto importante a ser destacado é que o trabalho a distância não pode invadir a criação corpórea do produto industrial: montagem, embalagem, transporte de mercadorias, por exemplo, pois todos esses fatores pressupõem a manipulação direta ou mesmo a presença física do trabalhador. Apenas para as atividades que utilizam a elaboração ou transmissão de dados, informações e símbolos, a superação do espaço físico pode ser concebível, ficando evidente, em alguns casos, que a distância é irrelevante para efeitos de controle e poder, pois a tecnologia utilizada configura-se como uma extensão da própria empresa.

Nesse âmbito, o que torna peculiar o teletrabalho - como será visto a seguir -é a combinação da distância física do trabalhador em face da empresa e a utilização de suporte de informática e telecomunicações, firmando uma permanente dinâmica entre os sujeitos da relação jurídica, com impactos marcantes na ordem socioeconômica.

\section{TRABALHO EM DOMICÍLIO}

Forma clássica de trabalho no período pré-industrial, o trabalho em domicílio, caracterizado pelo trabalho artesanal realizado na casa do trabalhador ou em oficina familiar, caracterizava-se pela produção a ser destinada essencialmente no atendimento das necessidades do grupo existente no mesmo círculo social.

Um conceito que bem define o trabalho em domicílio encontra-se presente no estudo de EVARISTO DE MORAES FILHO, que o considera "como sendo o que realiza o operário, habitual ou profissionalmente, em sua própria habitação ou em local por ele escolhido, longe da vigilância direta do empregador, ou em oficina de família, com auxílio dos parentes aí residentes ou algum trabalhador externo, sempre que o faça por conta e sob a direção de um patrão". ${ }^{5}$

As dificuldades para se analisar a exata dimensão do trabalho em domicílio se dão face às transformações que a sociedade vem sofrendo, desafiando o ordenamento jurídico a encontrar soluções para os conflitos que surgem com nova roupagem.

Denota-se, com isso, a preocupação da Organização Internacional do Trabalho (OIT) com o trabalho em domicílio, diante das mudanças tecnológicas que apontam o surgimento de novas figuras, assumindo, assim, uma relevância que não foi detida ao longo do período de produção fordista, ${ }^{6}$ pois tal forma de trabalho permaneceu em

4 Cf. HARVEY, David. Condição pós-moderna: uma pesquisa sobre as origens da mudança cultural. 8. ed. São Paulo: Edições Loyola, 1999, p. 140-141.

5 MORAES FILHO, Evaristo de. Trabalho a domicílio e contrato de trabalho. São Paulo: LTr, 1994, p. 74.

6 A reestruturação produtiva que vem substituindo o paradigma de produção fordista-taylorista pelo chamado pós-fordismo, flexibilizando a relação de trabalho, promoveu a reativação da prestação do trabalho em domicílio. 
caráter residual. Assim, a OIT adotou, em 04.06.1996, a Convenção $n^{\circ} 177$, tendo como objeto de análise o trabalho em domicílio. No entanto, essa convenção não leva em consideração as perspectivas que vêm sendo apontadas para o direito do trabalho, pois embora haja manifestação expressa acerca da matéria, o seu conteúdo não é suficientemente amplo para abranger as novas figuras que surgem no cenário social.

A problemática acerca do trabalho em domicílio aparece justamente em um momento histórico em que a utilização cada vez mais intensa dos mecanismos de comunicação a distância ditam um novo ritmo de produção em que o processo produtivo passa a ser substituído pelo resultado.

A Consolidação das Leis do Trabalho (CLT) ${ }^{7}$ dispõe acerca do trabalho em domicílio nos arts. $6^{\circ}$ e $83 . \mathrm{O}$ art. $6^{\circ}$ dispõe que: "Não se distingue entre o trabalho realizado no domicílio do empregador e o executado no domicílio do empregado, desde que esteja caracterizada a relação de emprego". Por sua vez, o art. 83 assegura o salário mínimo ao trabalhador em domicílio, considerado como "o executado na habitação do empregado ou em oficina de família, por conta de empregador que o remunere".

Observe-se que o art. $6^{\circ}$ não faz a distinção entre o trabalho realizado nas dependências físicas da empresa e aquele executado no domicílio do empregado, desde que haja a caracterização do vínculo de emprego, ou seja, é preciso que estejam presentes a subordinação, a habitualidade e a pessoalidade ${ }^{8}$ na prestação dos serviços.

Essas considerações são importantes para que se possa apreender alguns caracteres do trabalho em domicílio e fazer um comparativo dessa forma produtiva com o teletrabalho, embora este, ao contrário do trabalho em domicílio clássico, maximiza a utilização de tecnologia da informação, bem como o mesmo pode não ser prestado exclusivamente na residência do trabalhador.

\section{TELETRABALHO}

Fruto da sociedade contemporânea, o teletrabalho surge em um contexto no qual o sistema fabril clássico está em evidente declínio, ${ }^{9}$ ante as mudanças engendradas pela nova revolução industrial. Assim, a linha de montagem tradicional, que tem como símbolo maior o fordismo, passa a perder força, não obstante o processo produtivo baseado na unidade de tempo e lugar ainda ser a realidade de milhões de trabalhadores.

Com a implementação de novas tecnologias, principalmente informática e telecomunicações, e pela tendência de expansão do setor de serviços, surgiram novas

7 Legislação brasileira que regula os conflitos de interesses entre capital e trabalho, datada de 1943.

8 A pessoalidade se faz necessária, pois se o trabalhador é substituído por familiar na prestação dos serviços, não se caracteriza o vínculo empregatício, cujos requisitos estão presentes nos arts. $2^{\circ}$ e $3^{\circ}$, da CLT.

9 Esse sistema era fundado na divisão do processo de produção, no controle rígido do horário de trabalho, na hierarquização das relações, na alienação e mecanização do trabalho e no local específico para a realização das atividades. 
formas de trabalho que possibilitaram a redução dos custos de produção das empresas e o aumento da competitividade. Assim, percebeu-se que, com a utilização destes meios tecnológicos, não era mais preciso comparecer diariamente ao trabalho para se realizar as tarefas, as quais poderiam ser executadas na residência do empregado ou em outros locais, e enviadas posteriormente à empresa. E é nesse contexto que surge o teletrabalho, o qual está funcionalmente limitado ao domínio da informação.

Então, importante destacar alguns elementos básicos que diferenciam o teletrabalho de outras formas de execução no processo produtivo, quais sejam basicamente: a) utilização de novas tecnologias, em especial a de telecomunicações, informática, com os instrumentos a eles inerentes, tais como o telefone, computador, fax, secretária eletrônica. Como menciona VALENTIM, o importante é o "incremento de novas tecnologias (fibras óticas, comunicação por satélite, telefonia digital, por exemplo)"; ${ }^{10}$ b) a prestação de serviços ocorre geralmente na residência do teletrabalhador, mas pode se dar em telecentros ou de forma nômade, sem um local fixo e certo, podendo também o teletrabalhador cumprir parte de sua jornada na empresa e, a outra parte, longe dos olhos do empregador; c) a permanente troca de informações entre os sujeitos da relação, não exigindo o contato direto, pessoal e contínuo, eis que quase todos os atos se dão por meio da Internet ou mesmo por linha telefônica.

Consoante o já acima descrito, o teletrabalho pode ser realizado em telecentros, em domicílio ou mesmo de forma nômade ou móvel.

Os telecentros são locais situados fora da sede principal da empresa, descentralizados. Podem ser divididos em subespécies, ${ }^{11}$ em que a mais importante é o centro satélite, local pertencente à própria empresa, ${ }^{12}$ que, segundo ROSARIO GALLARDO MOYA, trata-se de pequeno estabelecimento separado da sede central, mas que com ela está em permanente comunicação eletrônica. ${ }^{13}$ Outra subespécie é o telecentro desenvolvido em locais descentralizados, providenciados pela própria empresa, a qual oferece, mediante aluguel, instalações de informática e de telecomunicações que podem ser compartilhados por diversos usuários, sejam empresas ou pessoas físicas. Há ainda uma terceira subespécie, que é o centro compartilhado ou comunitário, denominado pelos americanos e ingleses de "ABC" (advance business center), em que coexistem teletrabalhadores vinculados a vários empregadores e até profissionais independentes.

O teletrabalho realizado em domicílio se dá pela mesma forma que o trabalho em domicílio tradicional, sendo realizado pelo trabalhador em sua residência ou em ambiente familiar, com as mesmas características já anteriormente abordadas em item específico.

10 VALENTIM, João Hilário. Teletrabalho e relações de trabalho. In: Revista Gênesis de Direito do Trabalho, n. 82, p. 524-530, 1999.

11 Modalidades propostas por PEDREIRA, P. Op. cit., p. 584.

12 PINHO PEDREIRA denomina de "centro satélite". Op. cit., p. 584.

13 MOYA, R. G. El viejo y el nuevo trabajo a domicilio; de la máquina de hilar al ordenador. Madri: Ibidem Ediciones, 1998, p. 60. 
Por fim, o teletrabalho nômade ou móvel é a aquele realizado pelos trabalhadores que não possuem local fixo e apropriado e na maior parte do tempo se encontram nas ruas, assumindo a feição de atividade itinerante. ${ }^{14}$

Calcula-se que nos EUA $65 \%$ da força de trabalho seja formada por trabalhadores da informação, sendo que mais de 70 milhões de pessoas trabalham em casa. Já o Ministério do Trabalho Britânico estima que 3 milhões de pessoas, em uma população ativa de 27 milhões, trabalham atualmente em seus domicílios. ${ }^{15}$

Há autores que antevêem um grande crescimento do teletrabalho ao longo dos anos; outros, sociólogos, juristas e economistas, fazem vistas grossas ao fenômeno. De qualquer forma, ainda que não se consiga fazer uma estimativa segura, tudo indica que a sociedade mundial ainda se encontra perante uma modalidade de trabalho inexpressiva. Porém, é inequívoca a expansão desta nova atividade que, sem dúvida, vive em uma fase embrionária.

\subsection{Definição}

Normalmente o termo "teletrabalho" tem sido empregado para expressar situações que não refletem adequadamente o fenômeno. Equivocam-se aqueles que afirmam que se trata simplesmente de trabalho em domicílio, ${ }^{16}$ pois em que pese muitas vezes tal mister ser realizado na residência do empregado, o mesmo pode ser realizado em telecentros ou mesmo de forma nômade, podendo o trabalhador laborar alguns dias da semana em casa e, outros, na empresa; além do que, há um diferencial que é a utilização de tecnologia das telecomunicações e informática.

Atribui-se a paternidade da expressão teletrabalho a JACK NILES, quando o mesmo, em 1973, em plena crise petrolífera, posicionou-se a favor da redução do consumo de petróleo, que se daria por meio do deslocamento do trabalho até às pessoas, ao contrário destas se dirigirem ao local de trabalho. ${ }^{17}$ Definiu essa estratégia como

14 MOYA, R.G. Op. cit., p. 60-61.

15 Cf. TROPE, Alberto. Organização virtual: impactos do teletrabalho nas organizações. Rio de Janeiro: Qualitymark, 1999, p. 15.

16 CHARLES GRANTHAM afirma que o teletrabalho está morto. Para ele, trata-se de um "conceito ultrapassado que se transformou naquilo que chamo de trabalho distribuído. Teletrabalho significava um empregado de uma empresa que trabalhava em casa uma ou duas vezes por semana. Com o advento da Internet, isto foi estendido para trabalhar em qualquer lugar, em qualquer hora do dia. Agora temos uma nova forma de trabalho-distância/tempo/colaboração/- e as pessoas estão tornando-se trabalhadores em part-time, contratadoras e similares. Então, a tecnologia moveu-se do simples 'tele' para a web e o trabalho moveu-se dos assalariados para os trabalhadores independentes. O trabalho tornou-se mais complexo, mais criativo e mais colaborativo numa arena internacional". GRANTHAM, Charles. Gurus do teletrabalho em confronto. Disponível em: http: //www.janelanaweb.com/reinv/entrev_gurus (capturado em 08.01.2003). De qualquer forma, há muito mais convergência do que divergência entre o teletrabalho e o trabalho em domicílio, tanto que, para efeito de aplicabilidade da legislação trabalhista, reputamos necessário fazer uma interpretação extensiva dos arts. $6^{\circ} \mathrm{e} 83$, da CLT, para o enquadramento jurídico da figura do teletrabalhador, como será visto adiante.

17 Para tal inversão, NILES utilizou a expressão telecommuting. 
"qualquer forma de substituição de deslocamentos relacionados com a atividade laboral por tecnologias de informação". ${ }^{18}$

A OIT define o teletrabalho como "forma de trabalho efetuada num lugar distanciado do escritório central ou do centro de produção e que implica uma nova tecnologia que permite a separação e facilita a comunicação". ${ }^{19}$ Por sua vez, especialistas da Fundação Européia para a Melhoria das Condições de Vida e de Trabalho conceituam como "qualquer forma de trabalho desenvolvida por conta de um empresário ou de um cliente, por um trabalhador dependente, um trabalhador autônomo ou um trabalhador em domicílio, efetuada regularmente e durante uma parte importante do tempo de trabalho de um ou mais lugares distintos do ponto de trabalho tradicional, utilizando tecnologia de informática e/ou de telecomunicações". ${ }^{20}$

DI MARTINO e WIRTH definem teletrabalho como aquele efetuado em um lugar distanciado das oficinas centrais de produção, sendo que o trabalhador não mantém contato pessoal com seus colegas e somente está em condições de se comunicar com eles por meio de novas tecnologias. ${ }^{21}$ Já VALENTIM propõe o seguinte conceito: "teletrabalho é a prestação de serviço destinada a outrem e sob a subordinação deste, exercida por um trabalhador, preferencialmente em sua casa e com o suporte de modernos instrumentos e tecnologias relacionados às telecomunicações e informática". ${ }^{22}$

Os conceitos acima citados se deram no intuito de privilegiar um debate acadêmico, por meio de um substrato teórico que se faz necessário para se compreender tal fenômeno em sua plenitude, tendo em vista que há elementos aparentemente não palpáveis no traço característico do teletrabalho, o que dificulta a postulação de um conceito uniforme e ordenado.

\subsection{Subjetividade do tempo de trabalho e a subordinação jurídica como critério definidor da relação de emprego}

Torna-se importante verificar os impactos do teletrabalho no tempo de trabalho, eis que, na sociedade atual, a utilização das tecnologias da informação influenciam o modo de organização, administração e controle do tempo.

Um dos aspectos mais interessantes diz respeito ao afastamento físico do trabalhador na empresa e a possibilidade ou não de implicar uma atenuação da subordinação do trabalhador em relação ao empregador. A descentralização do trabalho induz a se fazer uma valoração equivocada, pugnando pela autonomia do trabalho, por

18 Tradução livre do autor. Ver NILES, Jack. The tele communicationas: transportationa trade off. Options for tomorrow and today. California: Tala Internacional, 1973, apud ARANDA, J. T., op. cit., p. 24.

19 Tradução livre do autor. Ver em ARANDA, J. T. Op. cit., p. 24.

20 Tradução livre do autor. Cf. ARANDA, J. T. Op. cit., p. 24.

21 DI MARTINO, Vittorio; WIRTH, Linda. Teletrabajo: um nuevo modo de trabajo y de vida. In: Revista Internacional del Trabajo. Genebra; OIT, 109 (4): 471, 1990.

22 Op. cit., p. 526-527. 
haver um suposto desprendimento do controle do tempo e do ritmo de trabalho, tal qual se deu no sistema clássico industrial.

Assim, a forma pela qual o teletrabalho é realizado, em qualquer de suas modalidades já mencionadas, pode induzir alguém a pensar que tal modelo de produção se configura como trabalho autônomo, eis que a subordinação é vista de forma mitigada e difusa. Porém, trata-se de pré-juízo e de uma visão equivocada acerca de um trabalho cuja produção científica ainda é pequena e pouco explorada, devido à dificuldade de enquadramento de tal modelo produtivo, bem como devido à complexidade das relações de trabalho instauradas após a implementação de medidas de flexibilização e de redução de custos de mão-de-obra.

Com o teletrabalho, abre-se a possibilidade de mudança do controle do tempo de trabalho para o controle dos resultados, havendo a passagem de uma cultura de "compra do tempo", proveniente da organização tradicional, para a cultura da "compra do resultado", fruto da organização informatizada. ${ }^{23}$ Assim, as discussões acerca da separação do tempo de trabalho e do tempo livre passam por um necessário redimensionamento, pois o local de trabalho na empresa tende a perder força com o teletrabalho. ${ }^{24}$

O teletrabalho não apresenta qualquer especificidade teórica e, por conseguinte, o critério distintivo da autonomia e subordinação funda-se na existência ou não dos requisitos caracterizadores da relação de emprego. ${ }^{25}$

A avaliação da existência ou não de autonomia também implica a análise acerca da propriedade dos instrumentos de trabalho, pois se a escolha, organização e manutenção dos equipamentos competirem à empresa, certamente corresponderá ao estabelecimento de um vínculo empregatício.

Porém, apenas os critérios de subordinação existentes não oferecem total segurança para que o teletrabalho seja enquadrado ou não como autônomo. Vê-se que a complexidade é tão grande que, se de um lado, pressupõe-se a inexistência de controle de jornada pelo fato de o teletrabalhador prestar serviços fora do espaço físico da empresa, de outro lado, as atividades realizadas em telecentros - locais definidos pelo empregador - facilitam a possibilidade de existência de indícios de que tais indivíduos estejam sujeitos mais claramente às diretivas dos superiores, como se estivessem na sede da empresa, com os mesmos deveres e direitos (horários de trabalho, intervalos ...).

23 O empregador deixa de se preocupar mais com os meios utilizados para se preocupar com o resultado, ou seja, com a realização da meta fixada.

24 Em um momento histórico em que se discute a possibilidade de diminuição do tempo de trabalho como forma de os trabalhadores redimensionarem os espaços de lazer e de liberdade, além de servir como alternativa ao desemprego, a dinâmica capitalista cria uma nova figura, o teletrabalhador, que gradativamente aumenta pelo mundo.

Arts. $2^{\circ}$ e $3^{\circ}$, ambos da CLT. 
Diante de tal problemática, MOYA defende que a qualificação jurídica dos teletrabalhadores "não é a única, mas dependerá do modo como se leve a cabo a prestação, isto é, do seu conteúdo obrigacional. Em caráter geral, pode-se afirmar que o vínculo entre o que presta um serviço de teletrabalho e o que o recebe tanto poderá ser de natureza comercial, quanto civil ou trabalhista ...". ${ }^{26}$

A natureza jurídica do teletrabalho dependerá da forma pela qual é realizada a prestação de serviços, podendo assumir feição autônoma ou subordinada, dependendo da realidade vivenciada pelo trabalhador no ambiente empresarial ou extra-empresarial. Quando a autonomia estiver presente na prestação dos serviços, assumindo o autônomo os riscos de sua atividade e do empreendimento, não será de emprego a relação havida entre as partes. Porém, deve-se ter em mente que o teletrabalho poderá ser um instrumento utilizado pelas empresas - em decorrência da reengenharia ou downsizing - com o intuito de fraudar direitos dos trabalhadores, simulando contratos autônomos, além de sonegação fiscal.

Importante ressaltar que a nova tecnologia utilizada via informática e telecomunicações, por si só, não faz desaparecer a subordinação como categoria jurídica, ${ }^{27}$ mas apenas provoca uma alteração da morfologia do trabalho subordinado clássico, a partir do instante em que se submete o trabalhador a um poder de vigilância por meio de sistemas eletrônicos, permitindo ao empregador, inclusive, fiscalizar o trabalho de seus teletrabalhadores, caso estes, por exemplo, estejam conectados online com a empresa, por videofones ou mesmo por telefone. ${ }^{28}$

Sem dúvida, os novos modos de controle do trabalho implementados pela nova tecnologia reforçam ainda mais a subordinação do teletrabalhador, atingindo a vida privada deste, sendo que, em alguns casos, a subordinação pode estar presente de forma muito mais aparente do que em um trabalho realizado nas dependências da empresa. Nesse prisma, essa forma de trabalho acaba criando uma situação sui generis e análoga ao do trabalho clássico, podendo o empregador ter o controle da atividade dos teletrabalhadores por meio do próprio computador, pelo número de toques, por produção, horário de entrega dos relatórios, etc. ${ }^{29}$ Inclusive, algumas empresas britânicas e

26 Op. cit., p. 65.

27 ARANDA diz que "el teletrabajador se encuentra em conexión directa y permanente através de su ordenador com el centro de proceso de dado de la empresa, debiendo permanecer frente al mismo um número determinado de horas, lo que permitie no sólo um diálogo interactivo, sino también que el empleador pueda impartir instrucciones digitales y llevar a cabo uma supervisión y direccion". Op. cit., p. 44.

28 A conexão on-line, apesar de não ser nota distintiva, é um indício de subordinação, quando presente na interação entre trabalhador e empregador, sendo aquela que verdadeiramente caracteriza o teletrabalho. Isso não significa que as outras formas de conexão existentes induzam a existência da autonomia. Pelo contrário, o controle off-line se dá - via de regra - pelo resultado, mas o empregador pode se utilizar de outros mecanismos (telefone, por exemplo), em que o mesmo controlará o processo produtivo do empregado. Fala-se também em one way, em que a conexão se consubstancia num fluxo de dados ou informações do computador periférico para o central sem que haja a possibilidade de retorno. Trata-se de uma conexão de sentido único.

29 Cf. MARTINS, Sérgio Pinto Martins. Trabalho a distância. Trabalho \& doutrina, n. 24, 2000, p. 6. 
japonesas instalaram videofones nas residências dos teletrabalhadores com o objetivo de controlá-los, ${ }^{30}$ o que possibilita o registro do tempo de ativação do trabalhador, o número de telefonemas dado, gravação de voz e imagem, bem como a quantificação dos tempos de repouso, sendo que tais atos, por óbvio, ferem a imagem do trabalhador e atentam contra a sua intimidade.

\subsection{Enquadramento jurídico}

O teletrabalho ainda é um fenômeno em gestação nos países e a proteção legal específica para essa forma de trabalho, ao que se tem conhecimento, ainda não se concretizou. Dessa forma, as lacunas que surgem são muitas e a preocupação que assola os cientistas sociais se inquieta quanto à possível insuficiência da legislação vigente para efeitos de aplicabilidade em casos nos quais se verifique a forma de teletrabalho. Porém, ao contrário do sugerido, na verdade não se vê uma defasagem da disciplina jurídica para a regulação do teletrabalho.

A utilização da expressão teletrabalho deve ser conferida não somente aos teletrabalhadores que ocupam um posto de trabalho fora do espaço físico da empresa, como aqueles que apenas ocasionalmente trabalham à distância, e cumprem parte de sua jornada na empresa. Esta última forma talvez seja aquela que, hoje, mais esteja presente nas organizações e talvez por isso advenha a falta de notoriedade do seu enquadramento jurídico.

Antes de mais nada, observe-se que a dificuldade de enquadramento do teletrabalho não se revela solitária, pois o passado dá conta dos problemas de enquadramento do trabalho em domicílio, sendo que o direito brasileiro, de qualquer forma, adotou a solução legislativa para incluir o trabalhador em domicílio no conceito de empregado. Ocorre que o teletrabalho oferece outras características que não se encontram presentes necessariamente no trabalho em domicílio, por possuir a marca da implementação da informática e das telecomunicações, além de se constituir não necessariamente no domicílio do trabalhador.

No caso brasileiro, ainda que se coloque em dúvida a suficiência do critério da subordinação, haverá sempre a necessidade de se fazer a subsunção do caso concreto, pois o sistema jurídico é aberto, o que possibilita uma interpretação sistemática do ordenamento. De qualquer forma, não precisa fazer muito esforço para analisar quais as normas que se destinam ao teletrabalho, como espécie do trabalho à distância. Enquanto não houver sinal de mudança legislativa, a lógica deve ser feita primeiramente

30 Cf. TROPE, A. Op. cit., p. 77.

31 Ver $2^{\circ}$ e $3^{\circ}$, da CLT. Os requisitos fixados pela jurisprudência são: habitualidade, pessoalidade, subordinação e o pagamento de salário. Quanto a esse último requisito, questionamos sua aplicabilidade prática, eis que o pagamento dos salários, muitas vezes, não se concretiza na constância da relação de trabalho, o que se leva a presumir que tal trabalho se deu de forma voluntária, não havendo a caracterização da relação empregatícia, conforme muitas decisões judiciais assim absurdamente já decidiram 
na possibilidade de enquadramento do teletrabalho no âmbito trabalhista, ou seja, se de fato os elementos caracterizadores da relação de emprego encontram-se presentes. ${ }^{31}$ Assim, uma vez ultrapassada a análise concreta dos elementos caracterizadores do vínculo de emprego, já analisados no decorrer deste artigo, passa-se definitivamente ao seu enquadramento jurídico.

O legislador brasileiro obviamente ainda não pensava no teletrabalho quando da vigência da CLT, na década de 40 do século passado. Mas o tempo passou e a lei permaneceu vigente, restando a possibilidade, então, de se adequar os institutos que surgiram junto à letra fria da lei. Dessa forma, deve ser feita uma interpretação extensiva do art. $6^{\circ}$ da CLT, bem como do art. 83 celetário, pela própria valoração que a lei faz ao trabalho em domicílio, equiparando-o ao trabalho realizado no espaço físico da empresa. Quanto à jornada de trabalho, deverá ser analisado o caso concreto, verificando se a empresa utiliza mecanismos de controle da jornada ou não, mas é certo que a tendência seja pela aplicabilidade do art. 62, I, da CLT, também de aplicação extensiva aos teletrabalhadores.

No mais, em qualquer problemática que se instaure no âmbito da relação entre teletrabalhador e empregador, as regras trabalhistas serão aplicadas normalmente, jamais se devendo fechar os olhos para essa forma sui generis que já é realidade no cotidiano. O receio é de que o teletrabalho venha a alimentar a desestabilização de alguns alicerces jurídicos já consagrados ao longo dos tempos. Alguns elementos podem ser citados, como a heterodisponibilidade, devido ao interesse pelo resultado e não mais pelo processo produtivo; a fuga da regulação pelo tempo de trabalho, que pode vir a aliar o trabalho e o lazer a um só tempo, o que é vantajoso ao empregador, do ponto de vista empresarial, pois além de ter o funcionário à disposição, torna-o potencial consumidor; a ampliação do princípio do ius variandi ${ }^{32}$ a ingerência na esfera da vida privada do empregado, entre outros.

Deve ser estendido ao teletrabalhador todos os direitos dos trabalhadores que laboram sob a égide do sistema clássico pelo qual o direito do trabalho assentou suas bases, devendo estar integralmente abrangido pela legislação trabalhista, ${ }^{33}$ e sendo de responsabilidade do empregador, inclusive, o fornecimento dos equipamentos, bem como o custo decorrente da utilização do trabalho deve ser pago pelo empregador. ${ }^{34}$

32 Ver arts. 468 a 470, da CLT. O caput do art. 468 assim dispõe: "Nos contratos individuais de trabalho só é lícita a alteração das respectivas condições, por mútuo consentimento, e, ainda assim, desde que não resultem, direta ou indiretamente, prejuízos ao empregado, sob pena de nulidade da cláusula infringente dessa garantia".

33 Quanto à possibilidade de extensão de alguns direitos trabalhistas aos trabalhadores autônomos que se aventuram no teletrabalho, ainda é cedo para se propor algo, mas como modelo, há o exemplo italiano da chamada parassubordinação, em que, em situações excepcionais, dependendo da situação sóciojurídica face à proximidade desta categoria aos empregados, estendem-se alguns direitos a essa categoria de trabalhadores.

34 Tais como a linha telefônica e a energia elétrica. Entendemos que, quando o trabalhador utilizar seus próprios equipamentos, o mesmo deve ser reembolsado para cobrir os custos referentes ao desgaste dos equipamentos e pelas taxas fixas de telefonia e energia elétrica. 
Ademais, há obrigação de o empregador proporcionar boas condições de trabalho, pois, quer o teletrabalhador esteja no espaço físico da empresa, quer esteja num local descentralizado, há o dever de dotar o posto de trabalho de condições mínimas indispensáveis a um desempenho correto da função, do ponto de vista da saúde e segurança do trabalho.

Seja como for, denota-se a existência de uma vulnerabilidade inerente à relação de trabalho que se forma diante da existência de novas formas contratuais, o que, sem sombra de dúvida, trata-se de um problema muito mais de adequação da norma já existente do que propriamente da ausência de legislação trabalhista.

\subsection{Variáveis do teletrabalho: vantagens e inconvenientes}

Alguns estudiosos descrevem um cenário onde o teletrabalho conduziria a um melhor ambiente e qualidade de vida. ${ }^{35}$ Todavia, trata-se de uma teorização que esbarra na realidade dos fatos e na insuficiência dos números. De qualquer forma, pressupondo uma relação entre sujeitos em que o caráter sinalagmático é preservado, importa tecer algumas variáveis, positivas ou negativas, associadas à realização do teletrabalho.

Para os trabalhadores, há algumas vantagens como a diminuição da poluição ambiental e do congestionamento de tráfego, melhorando a qualidade de vida das pessoas, além de se evitar os gastos com transporte, perda de tempo com idas e vindas ao trabalho. O trabalhador também poderá ficar mais tempo em casa com a família, dedicando-se ao lazer, além de poder trabalhar de acordo com seu biorritmo e métodos pessoais, pois, teoricamente, o teletrabalho viabiliza para o trabalhador uma melhor possibilidade de gestão de seu tempo, potencializando a criatividade e responsabilidade individual.

O fator mais importante, sem dúvida, é a possibilidade de inserção no mercado de trabalho aos deficientes físicos e às mulheres, o que torna necessário, eis que em pleno início do século XXI, a sociedade ainda sofre as mazelas de uma discriminação que talvez décadas não sejam suficientes para o esquecimento dessa página escura da nossa história.

Ao contrário das vantagens que tal forma produtiva pode oferecer, os inconvenientes, principalmente do ponto de vista emocional, são muitos, como o isolamento do teletrabalhador de outros empregados da empresa, o que, até certo ponto,

35 Para o sociólogo do trabalho DOMENICO DE MASI, a utilização do teletrabalho permite uma enorme vantagem para empresas e trabalhadores: "Para as empresas há benefícios em termos de flexibilidade, produtividade e criatividade; para os trabalhadores há benefícios em termos de autonomia, condições físicas, relações familiares, boa vizinhança e acesso ao trabalho (sobretudo para deficientes físicos, anciãos, donas de casa); para a coletividade, há benefícios em termos de redistribuição geográfica e social do trabalho, redução do volume de trânsito, estímulos à criação de novos trabalhos, revitalização dos bairros, redução da poluição e das despesas de manutenção viária, eliminação das horas extras de pico etc." (DE MASI, Domenico. O futuro do trabalho: fadiga e ócio na sociedade pós-industrial. Rio de Janeiro: José Olympio; Brasília: UNB, 1999, p. 263-264). 
ficam impossibilitados de defender coletivamente seus direitos, dificultando o exercício de direitos sindicais devido à dispersão geográfica. Trata-se de um "desenraizamento social e psicológico que empobrece a experiência profissional, dificulta a continuidade de uma carreira, enfraquece as probabilidades de promoção e acarreta quebras salariais ...". 36

Também o teletrabalhador, dependendo do caso, pode vir a abrir mão de seguir uma carreira dentro da empresa, além do que pode aumentar suas despesas domésticas e vir a sofrer problemas relacionados à saúde, em razão da inadequação ergonômica dos móveis e instrumentos usados na execução do trabalho e excesso de tempo na utilização do computador, favorecendo o aparecimento de doenças ocupacionais. ${ }^{37}$ Assim, torna-se necessário implantar programas de treinamento em teletrabalho, bem como se fazer abordagens comportamentais e culturais para os teletrabalhadores, numa perspectiva de adaptação a essa forma produtiva.

Um aspecto a ser a ser analisado diz respeito ao sentimento de culpa que se instaura no teletrabalhador, tendo em vista as conseqüências de descontrole da atividade de trabalho, o que pode levar o trabalhador a laborar mais. Isso talvez decorra devido ao mascaramento da sensação de liberdade vivenciada pelos teletrabalhadores, os quais sentem a dificuldade de parar de trabalhar, já que os mesmos não se ausentam do local de trabalho ao fim da jornada. ${ }^{38}$

Já para o empregador, a vantagem se dá quanto à redução dos custos imobiliários e de mão-de-obra, ${ }^{39}$ face à modificação da produção de meio para uma produção de resultado, além da diminuição dos custos com o pagamento de horas extras, e a possibilidade de aumento da produtividade face à ausência de interrupções no trabalho. Porém, algumas vezes, os inconvenientes e custos para o empregador são tão grandes que a melhor saída certamente é a centralização das atividades, retomando novamente

36 Cf. REDINHA, Maria Regina Gomes. O teletrabalho. Disponível em: http://www.unicz.it /lavoro/ REDINHA (capturado em 10.01.2003)

37 Segundo dados colhidos do site da "Home Wireless Networks", apenas 37\% dos empregadores entrevistados nos EUA orientaram seus teletrabalhadores como produzir à distância e somente $41 \%$ deram aos mesmo algum preparo no tocante à saúde do trabalho remoto, ou seja, da montagem de seus locais de trabalho levando em consideração aspectos ergonômicos. Cf. JAMIL, George Leal. Teletrabalho: uma força na nova economia. Disponível em: http://www.widebiz.com.br/gente/jamil/ jamil_teletrabalho (capturado em 09.01.2003).

38 Um artigo publicado nos EUA revela que, em média, a carga de trabalho adicional de quem possui computador em casa chega a 164 horas por ano, o que equivale a mais de 20 dias. Fonte desconhecida.

39 A IBM da Espanha implantou o regime de teletrabalho, mobilizando cerca de $60 \%$ dos funcionários, sendo que tal medida ampliou as relações com os clientes para o dobro, além do que tal medida possibilitou reduzir em $50 \%$ os custos com aluguel e mobiliários. Também a empresa permitiu a cada funcionário escolher sua plataforma de informática e de comunicação, além de instituir um regime misto, com vindas ao escritório de uma a duas vezes por semana. Trata-se de um caso em que a empresa ganhou agilidade, flexibilidade, horizontalização, descentralização e aumento do grau de satisfação dos funcionários. RODRIGUES, Jorge Nascimento. A experiência da IBM España no teletrabalho. Disponível em: http://www.janelaweb.com/reinv/juan (capturado em 15.01.2003). 
a produção em seu sistema clássico, baseado no tempo e no lugar de prestação dos serviços. ${ }^{40}$

\section{CONSIDERAÇÕES FINAIS}

Deve-se debater acerca dos problemas mais visíveis do mundo atual, que é a crescente do trabalho à distância, especialmente o teletrabalho, pois é evidente a escassez de estudos acerca da matéria no Brasil e no Mercosul, face à promoção tardia do desenvolvimento industrial, fato pelo qual o trabalho em domicílio - fonte análoga assumiu apenas um caráter residual.

O teletrabalho, debatido timidamente na doutrina e ainda desconhecido na jurisprudência nacional, não parece afrontar a tentativa de enquadramento jurídico pela interpretação do ordenamento já existente. De qualquer forma, é surpreendente que no início do século XXI, em uma sociedade dominada pela tecnologia, discuta-se acerca de uma forma de prestação de serviço que possui relações estreitas com o sistema préindustrial.

O teletrabalho pode significar a melhoria substancial da relação de trabalho, aliando trabalho e lazer a um só tempo, possibilitando uma reabilitação do trabalho humano e a valorização da consciência profissional e da liberdade de criação. ${ }^{41}$ Mas pode também sofrer um efeito diverso, em que sua generalização pode acarretar a precarização no modo de dispor o trabalho e da própria integridade das categorias profissionais, tornando ineficaz a tutela do trabalho, a qual existe para equilibrar os sujeitos da relação jurídica.

Tal modelo capitalista, de fato, não é a solução para as novas formas de cooperação produtiva, pois algumas atividades e processos produtivos, bem como a resolução de problemas, carecerão do encontro direto das pessoas. Trata-se apenas de uma alternativa flexível de trabalho, mas que não resolve o problema do desemprego nem outras problemáticas sociais, principalmente por estar baseado na utilização de novas tecnologias da comunicação.

A sociedade deve estar envolvida para que a implementação do teletrabalho possibilite um avanço positivo no aprimoramento das relações sociais, conferindo ao teletrabalhador uma gama de direitos previstos em lei.

\section{REFERÊNCIAS BIBLIOGRÁFICAS}

ARANDA, Javier Thibault. El teletrabajo: análisis juridico-laboral. Madrid: Consejo Económico y Social, 2001.

40 Caso a empresa, por exemplo, tenha que fornecer conexão a Internet em alta velocidade para toda a equipe de funcionários teletrabalhadores, os custos podem ser altíssimos.

41 Muito longe da possibilidade de o teletrabalho atuar como força envolvida na mudança de paradigma da sociedade, ao contrário do que ALBERTO TROPE doutrina, afirmando que o teletrabalho "introduz nas organizações tradicionais, entorpecidas pelo positivismo e pela manutenção da ordem, a dialética transformadora do espaço e do tempo". Op. cit., p. 77. 
DE MASI, Domenico. O futuro do trabalho: fadiga e ócio na sociedade pós-industrial. Rio de Janeiro: José Olympio; Brasília: UNB, 1999.

DI MARTINO, Vittorio; WIRTH, Linda. Teletrabajo: um nuevo modo de trabajo y de vida. Revista Internacional del Trabajo. Genebra; OIT, 109 (4): 471, 1990.

GRANTHAM, Charles. Gurus do teletrabalho em confronto. Disponível em: http:// www.janelanaweb.com/reinv/entrev_gurus (capturado em 08.01.2003).

HARVEY, David. Condição pós-moderna: uma pesquisa sobre as origens da mudança cultural. 8. ed. São Paulo: Edições Loyola, 1999.

JAMIL, George Leal. Teletrabalho: uma força na nova economia. Disponível em: http:// www.widebiz.com.br/gente/jamil/jamil_teletrabalho (capturado em 09.01.2003).

MAGANO, Octavio Bueno. Trabalho a distância. In: Trabalho \& doutrina, n. 24, 2000.

MARTINS, Sérgio Pinto. Trabalho a distância. In: Trabalho \& doutrina, n. 24, 2000.

MORAES FILHO, Evaristo de. Trabalho a domicílio e contrato de trabalho. São Paulo: LTr, 1994.

MOYA, R. G. El viejo y el nuevo trabajo a domicilio; de la máquina de hilar al ordenador. Madri: Ibidem Ediciones, 1998.

NILES, Jack. The tele communicationas: transportationa trade off. Options for tomorrow and today. California: Tala Internacional, 1973.

PEDREIRA, P. O Teletrabalho. Revista LTr, v. 64, n. 5, 2000.

REDINHA, Maria Regina Gomes. O teletrabalho. Disponível em: http:/www.unicz.it/lavoro/ REDINHA (capturado em 10.01.2003).

RODRIGUES, Jorge Nascimento. A experiência da IBM España no teletrabalho. Disponível em: http://www.janelaweb.com/reinv/juan (capturado em 15.01.2003).

TRINDADE, W. L. da. Teletrabalho: trabalho a distância. In: RDT-Revista do Direito Trabalhista, n. 6, 2000.

TROPE, Alberto. Organização virtual: impactos do teletrabalho nas organizações. Rio de Janeiro: Qualitymark, 1999.

VALENTIM, João Hilário. Teletrabalho e relações de trabalho. In: Revista Gênesis de Direito do trabalho, n. 82, 1999. 